\title{
Validation of a Drug Transporter Probe Cocktail Using the Prototypical Inhibitors Rifampin, Probenecid, Verapamil, and Cimetidine
}

\author{
Sabrina T. Wiebe ${ }^{1,5}$. Thomas Giessmann ${ }^{1} \cdot$ Kathrin Hohl $^{1}$ - Sven Schmidt-Gerets ${ }^{1}$ - Edith Hauel ${ }^{1}$ - Alen Jambrecina ${ }^{2}$. \\ Kerstin Bader ${ }^{1}$. Naoki Ishiguro ${ }^{3} \cdot$ Mitchell E. Taub $^{4}$. Ashish Sharma ${ }^{4} \cdot$ Thomas Ebner $^{1} \cdot$ Gerd Mikus $^{5}$. \\ Martin F. Fromm ${ }^{6} \cdot$ Fabian Müller $^{1,6} \cdot$ Peter Stopfer $^{1}$
}

Published online: 5 June 2020

(c) The Author(s) 2020

\begin{abstract} to assess systemic exposure.

Clinical Trial Registration EudraCT number 2017-001549-29.

\section{Introduction}

Transporters play an important role in drug absorption, distribution and excretion; therefore, the inhibition of transporters by concomitantly administered drugs may cause clinically relevant drug-drug interactions (DDIs) [1-4]. Thus, a thorough investigation of transporter-mediated DDIs has become indispensable during drug development. Accordingly, the European Medicines Agency [5] and the US Food and Drug Administration [6] recommend in vitro studies to
\end{abstract}

Background and Objective A novel cocktail containing four substrates of key drug transporters was previously optimized to eliminate mutual drug-drug interactions between the probes digoxin (P-glycoprotein substrate), furosemide (organic anion transporter 1/3), metformin (organic cation transporter 2, multidrug and toxin extrusion protein 1/2-K), and rosuvastatin (organic anion transporting polypeptide 1B1/3, breast cancer resistance protein). This clinical trial investigated the effects of four commonly employed drug transporter inhibitors on cocktail drug pharmacokinetics.

Methods In a randomized open-label crossover trial in 45 healthy male subjects, treatment groups received the cocktail with or without single oral doses of rifampin, verapamil, cimetidine or probenecid. Concentrations of the probe drugs in serial plasma samples and urine fractions were measured by validated liquid chromatography-tandem mass spectrometry assays

Results The results were generally in accordance with known in vitro and/or clinical drug-drug interaction data. Single-dose rifampin increased rosuvastatin area under the plasma concentration-time curve up to the last quantifiable concentration $\left(\mathrm{AUC}_{0-\mathrm{tz}}\right)$ by $248 \%$ and maximum plasma concentration $\left(C_{\max }\right)$ by $1025 \%$. Probenecid increased furosemide $\mathrm{AUC}_{0-\mathrm{tz}}$ by $172 \%$ and $C_{\max }$ by $23 \%$. Cimetidine reduced metformin renal clearance by $26 \%$. The effect of single-dose verapamil on digoxin systemic exposure was less than expected from multiple-dose studies $\left(\mathrm{AUC}_{0-\mathrm{tz}}\right.$ unaltered, $\left.C_{\max }+22 \%\right)$.

Conclusions Taking all the interaction results together, the transporter cocktail is considered to be validated as a sensitive and specific tool for evaluating transporter-mediated drug-drug interactions in drug development.

Electronic supplementary material The online version of this article (https://doi.org/10.1007/s40262-020-00907-w) contains supplementary material, which is available to authorized users.

Peter Stopfer

Peter.Stopfer@boehringer-ingelheim.com

Extended author information available on the last page of the article ascertain and predict the effect of new investigational products on drug transporters known to be involved in clinically relevant in vivo drug interactions. If in vivo inhibition cannot be excluded based on in vitro data, an in vivo study is recommended by the European Medicines Agency and the Food and Drug Administration [5, 7].

A valuable method of investigating several separate mechanisms underlying DDIs in a single study with the investigational product as the perpetrator is the "cocktail approach". This method, in which a combination of wellcharacterized probe drugs is administered together with the new investigational product, is well established for investigation of cytochrome P450-mediated DDIs [8, 9]. In recent years, clinical studies to evaluate the cocktail approach for drug transporters have been conducted and published, which has in turn triggered interest from industry and regulatory authorities [10-14]. Both the European Medicines Agency and the Food and Drug Administration recommend the use 


\section{Key Points}

The probe-drug cocktail approach to efficiently investigate transporter-mediated drug-drug interactions is attracting increasing research interest. In previous clinical trials, we optimized a four-component cocktail comprising digoxin, furosemide, metformin, and rosuvastatin.

The cocktail was validated by investigating the effects of four prototypical inhibitors of drug transport (verapamil, rifampin, cimetidine, probenecid) on probe-drug systemic exposure in healthy subjects. The observed inhibitor effects on cocktail drug exposure proved for the first time sufficient sensitivity and specificity of a drug transporter cocktail.

The proposed cocktail is ready to be used as an effective, safe, and reliable option to investigate clinical drug-drug interaction potential involving key transporters (P-glycoprotein, organic anion transporter 1, organic anion transporter 3, organic cation transporter 2, multidrug and toxin extrusion protein 1 , multidrug and toxin extrusion protein $2-\mathrm{K}$, organic anion transporting polypeptide 1B1, organic anion transporting polypeptide 1B3, and breast cancer resistance protein) in the development of new drugs.

of cocktail studies for investigation of transporter-mediated DDIs [5, 7].

We have previously reported the development of a transporter cocktail comprising four well-characterized probe drugs. Based on available literature and in vitro data [15], four suitable marketed drugs (digoxin, metformin, furosemide, and rosuvastatin) were identified as probe substrates for key drug transporters involved in clinically relevant DDIs. Digoxin was selected as a substrate for P-glycoprotein (P-gp), furosemide for organic anion transporter 1 (OAT1) and organic anion transporter 1 (OAT3), metformin for organic cation transporter 2 (OCT2), multidrug and toxin extrusion protein 1 (MATE1) and multidrug and toxin extrusion protein 2-K (MATE2-K), and rosuvastatin for organic anion transporting polypeptide 1B1 (OATP1B1), for organic anion transporting polypeptide 1B3 (OATP1B3) and breast cancer resistance protein. Metabolism of these drugs is minor or negligible, facilitating investigation of transportermediated DDIs without enzyme inhibition potentially confounding the results.

In the course of three clinical trials in healthy volunteers $[10,16,17]$, the transporter probe drug doses were optimized to minimize mutual interactions. The final cocktail comprised $0.25 \mathrm{mg}$ of digoxin, $10 \mathrm{mg}$ of rosuvastatin, $10 \mathrm{mg}$ of metformin, and $1 \mathrm{mg}$ of furosemide. This optimized cocktail demonstrated no mutual interactions based on bioequivalence criteria applied to $\mathrm{AUC}_{0-\mathrm{tz}}$ (area under the plasma concentration-time curve from time zero to the last quantifiable concentration), $C_{\max }$ (maximum plasma concentration), and urinary excretion pharmacokinetic parameters of digoxin, furosemide, metformin, and rosuvastatin [17].

The aim of the present trial was to validate the use of this transporter cocktail as a reliable and safe method to determine clinically relevant DDIs by investigating the effect of prototypical drug transporter inhibitors on the probe substrates. In addition, the question was addressed whether different transporter inhibitory effects are observed when using therapeutic doses of the substrates metformin and furosemide compared to the subtherapeutic doses administered in the cocktail.

\section{Methods}

\subsection{Subjects}

Forty-five healthy male subjects aged $18-55$ years and with a body mass index of $18.5-29.9 \mathrm{~kg} / \mathrm{m}^{-2}$ participated in this trial (EudraCT number 2017-001549-29). Female subjects were not included, to avoid any potential confounding effect of the hormonal cycle or hormone-based contraception on the study results. The clinical trial protocol was approved by the Independent Ethics Committee of the Chamber of Physicians of Hamburg, Germany, and the Federal Institute for Drugs and Medicinal Products (BfArM). The trial was carried out in compliance with the principles of the Declaration of Helsinki and in accordance with the International Council for Harmonization Guidelines for Good Clinical Practice. All subjects provided written informed consent.

\subsection{Trial Objectives, Design, and Treatments}

This was a randomized, open-label, single-center crossover trial with a total of 11 treatments conducted in three parts. The primary objective was to determine the potential changes in drug concentrations of the transporter substrates digoxin $0.25 \mathrm{mg}$ (Lanicor ${ }^{\circledR} 0.25$-mg film-coated tablet; Teofarma S.r.l, Valle Salimbene, Italy), furosemide $1 \mathrm{mg}$ (Lasix ${ }^{\circledR}$ liquidum $10-\mathrm{mg} / \mathrm{mL}$ oral solution; Sanofi-Aventis Deutschland GmbH, Frankfurt am Main, Germany), metformin $10 \mathrm{mg}$ (MetfoLiquid GeriaSan ${ }^{\circledR} 1000$-mg/5-mL oral solution; Infectopharm Arzneimittel and Consilium $\mathrm{GmbH}$, Heppenheim, Germany), and rosuvastatin $10 \mathrm{mg}$ (Crestor ${ }^{\circledR}$ 10-mg film-coated tablet; AstraZeneca GmbH, Wedel, Germany) as a single dose [17] when administered together with drug transporter inhibitors compared to the cocktail alone. 
The inhibitors verapamil (Isoptin ${ }^{\circledR}$ 120-mg immediaterelease film-coated tablet; Mylan Healthcare GmbH, Troisdorf, Germany; inhibition of P-gp) and rifampin (Eremfat ${ }^{\circledR}$ 600 mg; Riemser Pharma GmbH, Greifswald-Insel Riems, Germany; OATP1B1/1B3 and breast cancer resistance protein) were tested in trial part 1 , cimetidine (Cimetidin acis ${ }^{\circledR}$ 400 mg; acis Arzneimittel GmbH, Grünwald, Germany; OCT2, MATE1/2-K) in part 2, and probenecid (Probenecid Weimer ${ }^{\circledR}$; Biokanol Pharma GmbH, Rastatt, Germany; OAT1/3) in part 3 . A further objective in parts 2 and 3 was to determine the inhibitory effects of cimetidine and probenecid on therapeutic doses of metformin $(500 \mathrm{mg})$ and furosemide (40 mg), respectively, compared to the subtherapeutic doses used in the cocktail.

In all three parts, a reference treatment with the cocktail alone was included and designated R1. Part 1 (12 subjects) comprised three treatment periods with three sequences, in which the two test treatments were cocktail plus verapamil and cocktail plus rifampin. The washout period between treatments was 13 days. Part 2 (17 subjects) and part 3 (16 subjects) each comprised four treatment periods, with four sequences and a washout period of 7 days. Part 2 comprised the test treatment cocktail plus cimetidine for comparison with R1, and an additional test/reference pair consisting of a reference treatment (R2) with metformin $500 \mathrm{mg}$ alone and a test treatment with metformin $500 \mathrm{mg}$ plus cimetidine. Part 3 comprised the test treatment cocktail plus probenecid for comparison with R1, and an additional test/reference pair consisting of a reference treatment (R3) with furosemide $40 \mathrm{mg}$ alone and a test treatment with furosemide $40 \mathrm{mg}$ plus probenecid.

For rifampin and probenecid, the dose regimens were selected based on literature data $[18,19]$. To avoid potential induction effects that have been observed following prolonged administration [20], verapamil was given as a single dose of $120 \mathrm{mg} 1 \mathrm{~h}$ before cocktail dosing and rifampin as a 600-mg single dose together with the cocktail. The cimetidine regimen was adapted from that used by Somogyi et al. [21] and $400 \mathrm{mg}$ was given $1 \mathrm{~h}$ prior to cocktail or metformin dosing with further doses administered $4 \mathrm{~h}, 8 \mathrm{~h}, 12 \mathrm{~h}$, $24 \mathrm{~h}$, and $36 \mathrm{~h}$ thereafter. Probenecid $1000 \mathrm{mg}$ was given on the day before cocktail or furosemide dosing, followed by $1000 \mathrm{mg} 1 \mathrm{~h}$ before administration of the cocktail or furosemide on the next day. The cocktail was administered with $280 \mathrm{~mL}$ of water after an overnight fast of at least $10 \mathrm{~h}$. Details of the trial design are given in the Electronic Supplementary Material (ESM).

\subsection{Pharmacokinetics}

Blood samples for the measurement of plasma concentrations of digoxin, furosemide, metformin, and rosuvastatin were taken using $\mathrm{K}_{3}$-EDTA as an anticoagulant from a forearm vein of each subject before dosing and at $20 \mathrm{~min}$, 40 min, 1, 1.5, 2, 2.5, 3, 4, 5, 6, 8, 10, 12, 24, 36, 47, 71, and $95 \mathrm{~h}$ after dosing. Urine samples were obtained before dosing and in the time intervals $0-4 \mathrm{~h}, 4-8 \mathrm{~h}, 8-12 \mathrm{~h}, 12-24 \mathrm{~h}$, and 24-36 h. Digoxin, furosemide, metformin, and rosuvastatin concentrations in plasma and urine were determined by validated liquid chromatography-tandem mass spectrometry assays according to the previously described methods and their minor modifications $[10,16,17]$. Digoxin was analyzed by Covance Laboratories Ltd, Harrogate, UK, and furosemide, metformin, and rosuvastatin by SGS Cephac Europe, St Benoît, France. Plasma samples were also taken around expected time to $C_{\max }$ for rifampin, verapamil, cimetidine, and probenecid, and samples were analyzed by SGS Cephac Europe. Precision and accuracy for the inhibitor assays were all within regulatory guidance-specified limits [22]. Inhibitor plasma concentrations are displayed in Table S6 of the ESM.

Pharmacokinetic parameters were calculated using standard noncompartmental methods with the software Phoenix WinNonlin ${ }^{\circledR}$ Professional, version 6.3 (Certara, Princeton, NJ, USA). For all analytes, the primary pharmacokinetic endpoints were $\mathrm{AUC}_{0-\mathrm{tz}}$ and $\mathrm{C}_{\max }$ and the secondary endpoint was $\mathrm{AUC}_{0-\infty}$ (area under the plasma concentration-time curve extrapolated to infinite time). Further endpoints were $\mathrm{CL}_{\mathrm{R}}$ (renal clearance) and fe (fraction excreted unchanged in urine) over 24 (metformin and furosemide) or 36 (digoxin and rosuvastatin) hours.

\subsection{Safety and Tolerability Assessment}

Safety and tolerability were assessed based on adverse events (AEs), 12-lead electrocardiograms, and vital signs. Clinically relevant findings in 12-lead electrocardiograms and vital signs were to be reported as AEs. Safety laboratory tests were conducted at screening, on day 2 of each period, and at the end of trial. The treated set (consisting of all subjects treated with at least one study drug) was used for safety analyses. Adverse events were analyzed according to the concept of treatment-emergent AEs and the number of subjects with AEs. Adverse events occurring within 8 days after the study drug intake were defined as treatment emergent and assigned to the corresponding treatment. Concomitant diagnoses and AEs were coded using the Medical Dictionary for Regulatory Activities version 19.1.

\subsection{Statistical Methods}

Statistical analyses were conducted separately for each trial part. The pharmacokinetic parameters of digoxin, furosemide, metformin, and rosuvastatin were compared when administered in the cocktail together with a transporter inhibitor (test treatment) or without the inhibitor (reference 
treatment). The test/reference ratios of the adjusted geometric means (GMR, geometric mean ratio) and their two-sided 90\% confidence intervals (CIs) were computed for the primary $\left(\mathrm{AUC}_{0-\mathrm{tz}}, C_{\max }\right)$ and secondary $\left(\mathrm{AUC}_{0-\infty}\right)$ pharmacokinetic endpoints and for the urinary parameters $\mathrm{CL}_{\mathrm{R}}$ and fe using an analysis of variance on the logarithmic scale including the effects 'sequence', 'subjects within sequence', 'period', and 'treatment'. The effect 'subjects within sequence' was random, whereas the other effects were fixed. Confidence interval and intra-individual geometric coefficient of variations were based on the residual error from the analysis of variance, thus considering all periods of the specific trial part. The geometric coefficient of variation presents the within-subject variability between treatments. The statistical analyses were performed using SAS ${ }^{\circledR}$ (version 9.4; SAS Institute Inc., Cary, NC, USA). For exploratory purposes, effects were considered relevant when the GMR point estimate was $\leq 80 \%$ (i.e., at least weakly induced) or $\geq 125 \%$ (at least weakly inhibited) [7].

The planned number of subjects to be entered into the trial, accounting for the dropout rate of $6-17 \%$ known from the previous trials $[10,16,17]$, was 47 , comprising 15 in part 1 and 16 each in parts 2 and 3 . The sample size was not based on a power calculation, but was judged to be adequate to attain reliable results and to fulfill the objectives and requirements of this exploratory trial. This is supported by the expected precision of the GMR estimate (defined as the ratio of the upper $90 \%$ CI limit to the point estimate), calculated according to the method of Kupper and Hafner [23], using $R$ version 3.2.2. A within-subject geometric coefficient of variation in the range of $10-25 \%$ for the primary pharmacokinetic endpoints was assumed, as observed in the previous trial [17].

\section{Results}

\subsection{Subjects}

Forty-five healthy male subjects (44 white, 1 Asian) were randomized and treated. In trial part 1 (12 subjects recruited of 15 planned), the mean age (standard deviation) was 39.3 (11.5) years and mean body mass index was $26.2(2.5) \mathrm{kg} /$ $\mathrm{m}^{2}$. The corresponding data for part 2 (17 subjects) were $37.2(10.7)$ years and $25.7(2.9) \mathrm{kg} / \mathrm{m}^{2}$, and for part 3 (16 subjects), $33.9(10.5)$ years and $24.7(2.8) \mathrm{kg} / \mathrm{m}^{2}$. Forty subjects completed the planned observation time according to protocol. In part 2, one subject was withdrawn because of non-compliance, one subject missed one period because of an influenza-like illness, and one subject did not receive treatment in period 3 owing to private reasons; one further subject had to be excluded from pharmacokinetic analyses because a medical condition became known only during the trial, which was a listed exclusion criterion that could affect the pharmacokinetics of the trial drugs. In part 3, two subjects did not receive all doses because of AEs attributed to probenecid.

\subsection{Pharmacokinetics}

\subsubsection{Trial Part 1: Rifampin or Verapamil as Inhibitors}

Geometric mean plasma concentration-time profiles of the transporter cocktail substrates with and without rifampin or verapamil are shown in Fig. 1. The primary endpoint pharmacokinetic parameters are given in Tables 1 and 2, and the urinary pharmacokinetic parameters in Tables $\mathrm{S} 1$ and $\mathrm{S} 2$ of the ESM. Forest plots of their GMRs and 90\% CIs are shown in Figs. S1 and S2 of the ESM. Rifampin increased rosuvastatin $C_{\max }$ and $\mathrm{AUC}_{0-\mathrm{tz}}$ by $1025 \%$ and $248 \%$, respectively. Digoxin $C_{\max }$ and $\mathrm{AUC}_{0-\mathrm{tz}}$ were increased by $118 \%$ and $31 \%$, respectively, and furosemide $C_{\max }$ was increased by $35 \%$. Metformin $C_{\max }$ and $\mathrm{AUC}_{0-\mathrm{tz}}$ were not impacted by rifampin. No relevant effects of verapamil on digoxin were observed ( $C_{\text {max }}$ : only a $22 \%$ increase; $\mathrm{AUC}_{0-\mathrm{tz}}$ and $\mathrm{CL}_{\mathrm{R}}$ : unchanged) and no effect of verapamil on rosuvastatin, furosemide, or metformin systemic exposure was noted.

\subsubsection{Trial Part 2: Cimetidine as an Inhibitor}

Geometric mean plasma concentration-time profiles of the transporter cocktail substrates with and without cimetidine are shown in Fig. 2, together with plasma profiles of metformin where it was dosed alone at the therapeutic concentrations of $500 \mathrm{mg}$ with or without cimetidine. The corresponding plasma and urinary pharmacokinetic parameters are given in Table 3 and Table S3 of the ESM, respectively, and the forest plots in Fig. S3 of the ESM. Cimetidine treatment increased $\mathrm{AUC}_{0-\mathrm{tz}}$ of digoxin by $26 \%$, but had no effect on furosemide systemic exposure. Cimetidine increased metformin $C_{\max }$ by $23 \%$ and $\mathrm{AUC}_{0-\mathrm{tz}}$ by $31 \%$ in the cocktail (10 $\mathrm{mg}$ of metformin), whereas the effects were greater when $500 \mathrm{mg}$ of metformin was administered, with a $41 \%$ increase for $C_{\max }$ and a $51 \%$ increase for $\mathrm{AUC}_{0-\mathrm{tz}}$. The difference in cimetidine inhibition between the metformin cocktail and therapeutic doses was, however, less pronounced for $\mathrm{CL}_{\mathrm{R}}$ (decreases of $26 \%$ and $35 \%$, respectively; Table $\mathrm{S} 3$ of the ESM). Calculation of renal secretory clearance showed decreases of $32 \%$ and $47 \%$, respectively. Cimetidine had no effect on rosuvastatin systemic exposure parameters.

\subsubsection{Trial Part 3: Probenecid as an Inhibitor}

Geometric mean plasma concentration-time profiles of the transporter cocktail substrates with and without probenecid are shown in Fig. 3, together with plasma profiles of 

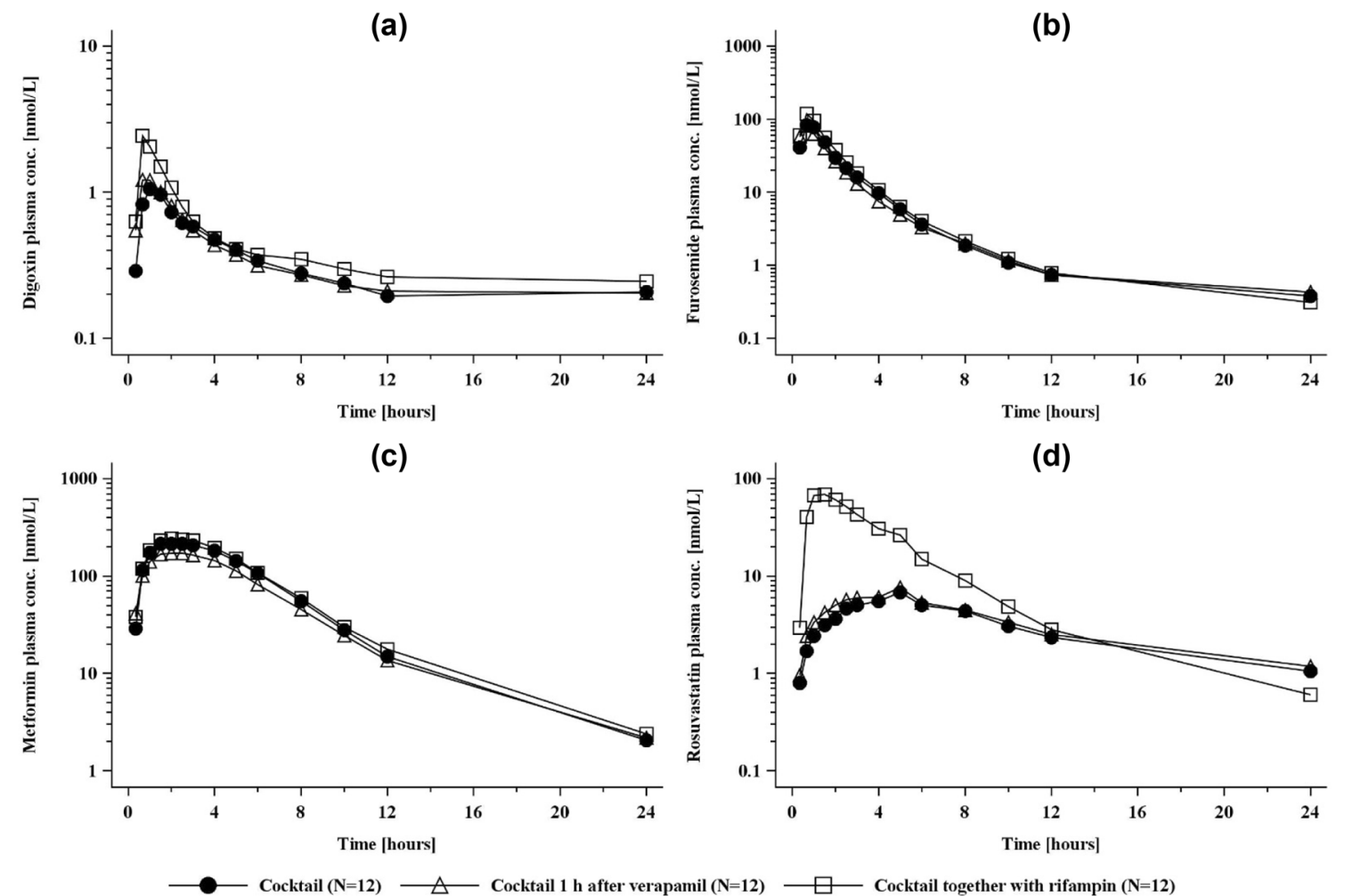

Fig. 1 Plasma concentration-time profiles (geometric mean) of a digoxin, $\mathbf{b}$ furosemide, $\mathbf{c}$ metformin, and $\mathbf{d}$ rosuvastatin after administration of a single oral dose of the cocktail given alone or in combination with verapamil or rifampin. conc. concentration

Table 1 Trial part 1: adjusted geometric means (Adj. gMean), geometric mean ratios, and $90 \%$ confidence intervals (CIs) for the primary pharmacokinetic parameters of digoxin, furosemide, metformin, and rosuvastatin administered as a cocktail with and without the inhibitor rifampin

\begin{tabular}{|c|c|c|c|c|c|c|c|}
\hline \multirow[t]{3}{*}{ Endpoint } & \multicolumn{2}{|c|}{ Test $(T)$} & \multicolumn{2}{|c|}{ Reference $(\mathrm{R})$} & \multirow{3}{*}{$\begin{array}{l}\text { Ratio T/R } \\
\%\end{array}$} & \multirow{3}{*}{$\begin{array}{l}90 \% \mathrm{CI} \\
\%\end{array}$} & \multirow{3}{*}{$\begin{array}{l}\mathrm{gCV} \\
\%\end{array}$} \\
\hline & \multicolumn{2}{|c|}{ Cocktail+ rifampin } & \multicolumn{2}{|c|}{ Cocktail alone } & & & \\
\hline & $N$ & Adj. gMean & $N$ & Adj. gMean & & & \\
\hline \multicolumn{8}{|l|}{ Digoxin } \\
\hline $\mathrm{AUC}_{0-\mathrm{tz}}(\mathrm{nmol} \cdot \mathrm{h} / \mathrm{L})$ & 12 & 17.89 & 12 & 13.61 & 131.41 & $115.93-148.97$ & 17.9 \\
\hline$C_{\max }(\mathrm{nmol} / \mathrm{L})$ & 12 & 2.55 & 12 & 1.17 & 218.26 & $180.19-264.36$ & 27.7 \\
\hline \multicolumn{8}{|l|}{ Furosemide } \\
\hline $\mathrm{AUC}_{0-\mathrm{tz}}(\mathrm{nmol} \cdot \mathrm{h} / \mathrm{L})$ & 12 & 211.82 & 12 & 176.85 & 119.78 & $110.03-130.39$ & 12.1 \\
\hline$C_{\max }(\mathrm{nmol} / \mathrm{L})$ & 12 & 119.66 & 12 & 88.59 & 135.07 & $117.83-154.84$ & 19.6 \\
\hline \multicolumn{8}{|l|}{ Metformin } \\
\hline $\mathrm{AUC}_{0-\mathrm{tz}}(\mathrm{nmol} \cdot \mathrm{h} / \mathrm{L})$ & 12 & 1473.38 & 12 & 1357.34 & 108.55 & $100.68-117.03$ & 10.7 \\
\hline $\mathrm{C}_{\max }(\mathrm{nmol} / \mathrm{L})$ & 12 & 251.32 & 12 & 223.78 & 112.31 & $102.26-123.35$ & 13.4 \\
\hline \multicolumn{8}{|l|}{ Rosuvastatin } \\
\hline $\mathrm{AUC}_{0-\mathrm{tz}}(\mathrm{nmol} \cdot \mathrm{h} / \mathrm{L})$ & 12 & 303.81 & 12 & 87.29 & 348.06 & $299.64-404.31$ & 21.5 \\
\hline$C_{\max }(\mathrm{nmol} / \mathrm{L})$ & 12 & 77.00 & 12 & 6.84 & 1125.10 & $914.63-1384.00$ & 30.1 \\
\hline
\end{tabular}

$A U C_{0-t z}$ area under the plasma concentration-time curve up to the last quantifiable concentration, $C_{\max }$ maximum plasma concentration, $g C V$ geometric coefficient of variation

${ }^{a}$ Within-subject $g C V$ furosemide where it was dosed at the therapeutic concentration of $40 \mathrm{mg}$ with or without probenecid. The corresponding plasma and urinary pharmacokinetic parameters are given in Table 4 and Table S4 of the ESM, respectively, and the forest plots in Fig. S4 of the ESM. Probenecid treatment increased $C_{\max }$ and $\mathrm{AUC}_{0-\mathrm{tz}}$ of rosuvastatin by $328 \%$ and $123 \%$, respectively, and decreased its $\mathrm{CL}_{\mathrm{R}}$ by $78 \%$. There was no effect on the systemic exposure to digoxin 
Table 2 Trial part 1: adjusted geometric means (Adj. gMean), geometric mean ratios, and $90 \%$ confidence intervals (CIs) for the primary pharmacokinetic parameters of digoxin, furosemide, metformin, and rosuvastatin administered as a cocktail with and without the inhibitor verapamil

\begin{tabular}{|c|c|c|c|c|c|c|c|}
\hline \multirow[t]{3}{*}{ Endpoint } & \multirow{2}{*}{\multicolumn{2}{|c|}{$\begin{array}{l}\text { Test }(T) \\
\text { Cocktail + vera- } \\
\text { pamil }\end{array}$}} & \multirow{2}{*}{\multicolumn{2}{|c|}{$\frac{\text { Reference (R) }}{\text { Cocktail alone }}$}} & \multirow{3}{*}{$\begin{array}{l}\text { Ratio T/R } \\
\%\end{array}$} & \multirow{3}{*}{$\begin{array}{l}90 \% \mathrm{CI} \\
\%\end{array}$} & \multirow{3}{*}{$\begin{array}{l}\mathrm{gCV}^{\mathrm{a}} \\
\%\end{array}$} \\
\hline & & & & & & & \\
\hline & $N$ & Adj. gMean & $N$ & Adj. gMean & & & \\
\hline \multicolumn{8}{|l|}{ Digoxin } \\
\hline $\mathrm{AUC}_{0-\mathrm{tz}}(\mathrm{nmol} \cdot \mathrm{h} / \mathrm{L})$ & 12 & 13.71 & 12 & 13.61 & 100.70 & $88.84-114.15$ & 17.9 \\
\hline$C_{\max }(\mathrm{nmol} / \mathrm{L})$ & 12 & 1.42 & 12 & 1.17 & 121.64 & $100.43-147.33$ & 27.7 \\
\hline \multicolumn{8}{|l|}{ Furosemide } \\
\hline $\mathrm{AUC}_{0-\mathrm{tz}}(\mathrm{nmol} \cdot \mathrm{h} / \mathrm{L})$ & 12 & 165.80 & 12 & 176.85 & 93.76 & $86.12-102.06$ & 12.1 \\
\hline$C_{\max }(\mathrm{nmol} / \mathrm{L})$ & 12 & 84.32 & 12 & 88.59 & 95.18 & $83.03-109.11$ & 19.6 \\
\hline \multicolumn{8}{|l|}{ Metformin } \\
\hline $\mathrm{AUC}_{0-\mathrm{tz}}(\mathrm{nmol} \cdot \mathrm{h} / \mathrm{L})$ & 12 & 1126.22 & 12 & 1357.34 & 82.97 & $76.96-89.46$ & 10.7 \\
\hline$C_{\max }(\mathrm{nmol} / \mathrm{L})$ & 12 & 179.45 & 12 & 223.78 & 80.19 & $73.01-88.08$ & 13.4 \\
\hline \multicolumn{8}{|l|}{ Rosuvastatin } \\
\hline $\mathrm{AUC}_{0-\mathrm{tz}}(\mathrm{nmol} \cdot \mathrm{h} / \mathrm{L})$ & 12 & 98.98 & 12 & 87.29 & 113.40 & $97.62-131.72$ & 21.5 \\
\hline$C_{\max }(\mathrm{nmol} / \mathrm{L})$ & 12 & 7.90 & 12 & 6.84 & 115.39 & 93.80-141.94 & 30.1 \\
\hline
\end{tabular}

$A U C_{0-t z}$ area under the plasma concentration-time curve up to the last quantifiable concentration, $C_{\max }$ maximum plasma concentration, $g C V$ geometric coefficient of variation

${ }^{\mathrm{a} W i t h i n-s u b j e c t ~ g C V}$ or metformin. Probenecid increased furosemide $\mathrm{AUC}_{0-\mathrm{tz}}$ by $172 \%$, and decreased $\mathrm{CL}_{\mathrm{R}}$ by $74 \%$ when the cocktail furosemide dose $(1 \mathrm{mg})$ was used. These effects on furosemide pharmacokinetics were of the same magnitude when $40 \mathrm{mg}$ of furosemide was administered alone; the corresponding increases were $47 \%$ for $C_{\max }$ and $203 \%$ for $\mathrm{AUC}_{0-\mathrm{tz}}$, with $\mathrm{CL}_{\mathrm{R}}$ reduced by $76 \%$. An overview of all effects is given in Table S5 of the ESM.

\subsection{Safety and Tolerability}

Treatment-emergent AEs were reported by 25 out of the 45 subjects (55.6\%). All AEs were of mild or moderate intensity. No serious AEs and only one "other significant AE" (according to the International Conference on Harmonization E3 definition) were reported. The affected subject was prematurely withdrawn from treatment in this treatment period because of AEs upon administration of probenecid (nausea, dizziness). The most frequently reported AEs included 'nasopharyngitis' $(25.0 \%)$ for part 1, 'headache' $(41.2 \%)$, and 'nausea' $(23.5 \%)$ for part 2, and 'headache' $(18.8 \%)$ for part 3 . There were no treatment-emergent clinically relevant findings in the clinical laboratory, electrocardiograms, or vital signs evaluations.

\section{Discussion}

This clinical phase I trial in healthy male subjects separately investigated the effect of four commonly employed inhibitors of drug transporters on the pharmacokinetics of the probe drugs of the four-component transporter cocktail that was developed and optimized previously [10, 16, 17], to validate the cocktail for further use in drug development. The effects of the four selected transporter inhibitors on the systemic exposure pharmacokinetic parameters of each cocktail probe drug could be determined with good precision in the three groups of healthy subjects, as measured by the GMRs and their $90 \%$ confidence intervals. Within-subject gCVs were in the range of 9.2-21.5\% for $\mathrm{AUC}_{0-\mathrm{tz}}, 12.0-30.1 \%$ for $C_{\max }$, and 9.4-24.5\% for $\mathrm{CL}_{\mathrm{R}}$ (Tables 1, 2, 3, 4 and Tables S1-S4 and Figs. S1-S3 of the ESM).

In trial part 1 , the effect of rifampin, used as an OATP1B1/1B3 and breast cancer resistance protein inhibitor, on the substrate rosuvastatin was large (Table 1 and Table S1 of the ESM), and the observed $1025 \%$ and $248 \%$ increases of $C_{\max }$ and $\mathrm{AUC}_{0-\mathrm{tz}}$, respectively, were in accordance with previous reports [24, 25]. The increased exposure of digoxin (Table 1) was also observed in a previous study [26] and is likely attributable to inhibition of intestinal P-gp and hepatic uptake via transporters such as OATPs [27]. No prior data have been published on the effects of rifampin on furosemide pharmacokinetics, but the observed increase in furosemide exposure correlates with in vitro findings showing that furosemide is a substrate of OATP1B1/1B3 and probably also MRP2 [15], whereas rifampin is an inhibitor of OATP1B1/1B3 [3] and possibly of MRP2 [28]. Metformin exposure in this trial was unchanged by rifampin as expected mechanistically, and agrees with previous findings showing that rifampin coadministration caused only a $10 \%$ increase [29]. 

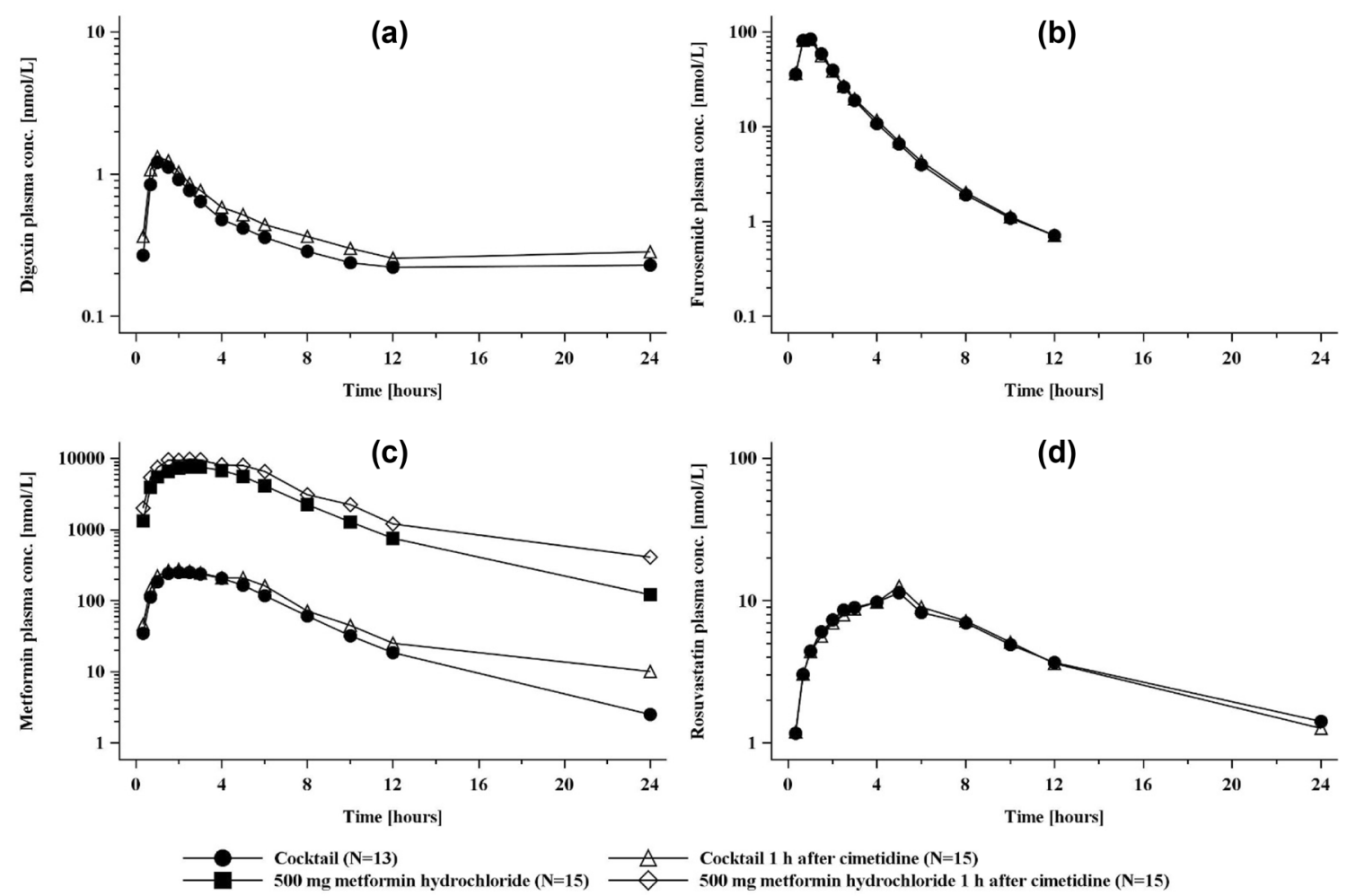

Fig. 2 Plasma concentration-time profiles (geometric mean) of a digoxin, $\mathbf{b}$ furosemide, $\mathbf{c}$ metformin, and $\mathbf{d}$ rosuvastatin after administration of a single oral dose of the cocktail given alone or in combina-

Verapamil as a P-gp inhibitor did not relevantly increase the systemic exposure of the substrate digoxin, as measured by only a $22 \%$ increase in $C_{\max }$, and unchanged AUC 0-tz (Table 2). This effect was less than expected based on literature findings, which reported a $44-77 \%$ increase in exposure [20, 30, 31]. However, in the previously reported studies, verapamil was administered over multiple days, whereas in the present trial only a single dose was used. It has been shown that verapamil may require 3-4 days of dosing to fully inhibit P-gp [32, 33]. Further, verapamil $C_{\max }$ was approximately $100 \mathrm{ng} / \mathrm{mL}$ or $0.2 \mu \mathrm{M}$ (Table S6 of the ESM), but according to Pauli-Magnus et al. [34], the halfmaximal inhibitory concentration for inhibition of digoxin transport by verapamil in Caco- 2 cells is about $1.1 \mu \mathrm{M}$. Therefore, verapamil concentrations were likely too low in the current trial to inhibit P-gp sufficiently in the liver and kidney. No relevant changes in exposures of the remaining substrates under verapamil were observed (Table 2 and Table $\mathrm{S} 2$ of the ESM), as expected mechanistically. Previous findings for metformin also showed no impact of verapamil on metformin concentrations [35], while no literature data are available for the effect of verapamil on rosuvastatin or furosemide. tion with cimetidine. Metformin data are shown in addition for a therapeutic dose given with or without cimetidine. conc. concentration

In trial part 2, cimetidine as an inhibitor of OCT2 and MATE1/2-K (for cimetidine plasma concentrations, refer to Table S6 of the ESM) produced an increase in the systemic exposure of the substrate metformin (Table 3 and Table S3 of the ESM), as was expected. However, with metformin dosed at $10 \mathrm{mg}$ in the cocktail, this effect was less than previously reported $[36,37]$. When the therapeutic metformin dose $(500 \mathrm{mg}$ ) was used, the effect of cimetidine was larger (Table 3) and was closer to previous findings of a $45-70 \%$ increase in metformin systemic exposure [36, 37]. However, considering the renal site of interaction, the effect of cimetidine on the $\mathrm{CL}_{\mathrm{R}}$ of metformin was also investigated. As shown in Table S3 of the ESM, the difference in the effect of cimetidine on the therapeutic vs the cocktail doses of metformin was less pronounced for metformin $\mathrm{CL}_{R}$ as compared with its plasma exposure parameters. Therefore, it may be more relevant to consider changes in the renal (secretory) clearance of metformin, rather than its plasma pharmacokinetic parameters, as a primary endpoint for upcoming DDI trials employing a metformin $10-\mathrm{mg}$ dose. Similar results were reported from a previous phase I trial that investigated the effect of the MATE inhibitor pyrimethamine on metformin pharmacokinetics at a therapeutic dose $(250 \mathrm{mg})$ and a microdose $(100 \mu \mathrm{g})$ [38], suggesting that the extent 
Table 3 Trial part 2: adjusted geometric means (Adj. gMean), geometric mean ratios, and $90 \%$ confidence intervals (CIs) for the primary pharmacokinetic parameters of digoxin, furosemide, metformin, and rosuvastatin administered as a cocktail with and without the inhibitor cimetidine

\begin{tabular}{|c|c|c|c|c|c|c|c|}
\hline \multirow[t]{3}{*}{ Endpoint } & \multicolumn{2}{|c|}{ Test $(T)$} & \multicolumn{2}{|c|}{ Reference (R) } & \multirow{3}{*}{$\begin{array}{l}\text { Ratio T/R } \\
\%\end{array}$} & \multirow{3}{*}{$\begin{array}{l}90 \% \mathrm{CI} \\
\%\end{array}$} & \multirow{3}{*}{$\begin{array}{l}\mathrm{gCV}^{\mathrm{a}} \\
\%\end{array}$} \\
\hline & \multicolumn{2}{|c|}{ Cocktail + cimetidine } & \multicolumn{2}{|c|}{ Cocktail alone } & & & \\
\hline & $N$ & Adj. gMean & $N$ & Adj. gMean & & & \\
\hline \multicolumn{8}{|l|}{ Digoxin } \\
\hline $\mathrm{AUC}_{0-\mathrm{tz}}(\mathrm{nmol} \cdot \mathrm{h} / \mathrm{L})$ & 15 & 19.03 & 13 & 15.15 & 125.61 & $113.99-138.43$ & 13.2 \\
\hline$C_{\max }(\mathrm{nmol} / \mathrm{L})$ & 15 & 1.65 & 13 & 1.35 & 122.03 & $103.04-144.52$ & 23.8 \\
\hline \multicolumn{8}{|l|}{ Furosemide } \\
\hline $\mathrm{AUC}_{0-\mathrm{tz}}(\mathrm{nmol} \cdot \mathrm{h} / \mathrm{L})$ & 15 & 196.39 & 13 & 194.05 & 101.21 & $94.59-108.30$ & 9.2 \\
\hline$C_{\max }(\mathrm{nmol} / \mathrm{L})$ & 15 & 97.69 & 13 & 93.23 & 104.78 & $89.97-122.03$ & 21.0 \\
\hline \multicolumn{8}{|l|}{ Metformin $^{\text {b }}$} \\
\hline $\mathrm{AUC}_{0-\mathrm{tz}}(\mathrm{nmol} \cdot \mathrm{h} / \mathrm{L})$ & 15 & 2006.60 & 13 & 1532.41 & 130.94 & $119.82-143.10$ & 13.6 \\
\hline$C_{\max }(\mathrm{nmol} / \mathrm{L})$ & 15 & 316.83 & 13 & 258.33 & 122.65 & 107.68-139.69 & 20.1 \\
\hline \multicolumn{8}{|l|}{ Rosuvastatin } \\
\hline $\mathrm{AUC}_{0-\mathrm{tz}}(\mathrm{nmol} \cdot \mathrm{h} / \mathrm{L})$ & 15 & 139.54 & 13 & 129.90 & 107.42 & $97.57-118.27$ & 12.9 \\
\hline$C_{\max }(\mathrm{nmol} / \mathrm{L})$ & 15 & 13.21 & 13 & 11.30 & 116.88 & $105.07-130.03$ & 14.4 \\
\hline \multirow[t]{3}{*}{ Endpoint } & \multicolumn{2}{|c|}{ Test $(T)$} & \multicolumn{2}{|c|}{ Reference (R) } & \multirow[t]{2}{*}{ Ratio T/R } & \multirow[t]{2}{*}{$90 \% \mathrm{CI}$} & \multirow[t]{2}{*}{$\mathrm{gCV}^{\mathrm{a}}$} \\
\hline & \multicolumn{2}{|c|}{ Metformin ${ }^{c}+$ cimetidine } & \multicolumn{2}{|c|}{ Metformin alone $e^{c}$} & & & \\
\hline & $N$ & Adj. gMean & $N$ & Adj. gMean & $\%$ & $\%$ & $\%$ \\
\hline $\mathrm{AUC}_{0-\mathrm{tz}}(\mathrm{nmol} \cdot \mathrm{h} / \mathrm{L})$ & 15 & $78,293.42$ & 15 & $51,909.16$ & 150.83 & $138.59-164.15$ & 13.6 \\
\hline$C_{\max }(\mathrm{nmol} / \mathrm{L})$ & 15 & $11,367.19$ & 15 & 8078.63 & 140.71 & $124.27-159.31$ & 20.1 \\
\hline
\end{tabular}

$A U C_{0-t z}$ area under the plasma concentration-time curve up to the last quantifiable concentration, $C_{\max }$ maximum plasma concentration, $g C V$ geometric coefficient of variation

${ }^{\mathrm{a}}$ Within-subject gCV

${ }^{\mathrm{b}}$ Metformin cocktail dose, $10 \mathrm{mg}$

${ }^{\mathrm{c}}$ Metformin therapeutic dose, $500 \mathrm{mg}$

of interactions with metformin as a victim may depend on metformin dose. The increased exposure of digoxin observed (Table 3) confirms an earlier report [39], but in vitro data did not suggest any inhibitory effect of cimetidine on P-gp [40]. Regarding furosemide, no pharmacokinetic literature is available to compare with our finding of no inhibition by cimetidine. In vitro, cimetidine dose-dependently inhibits both OAT1- and OAT3-mediated transport with half-maximal inhibitory concentration values reported as 492 and $92 \mu \mathrm{M}$, respectively [41]. The maximum cimetidine plasma concentrations in the current study were $4.24-11.1 \mu \mathrm{M}$, i.e., substantially lower than reported in vitro half-maximal inhibitory concentration values, which is in line with the observed lack of interaction. With regard to an interaction between cimetidine and rosuvastatin, limited available data in vitro suggest that no DDI was expected [40], which is consistent with the present in vivo results.

In trial part 3, probenecid as an inhibitor of OAT1 and OAT3 produced a substantial increase in exposure of the substrate furosemide (172-203\% for $\mathrm{AUC}_{0-\mathrm{tz}}$ ), which was similar in magnitude for the cocktail dose $(1 \mathrm{mg})$ and therapeutic dose $(40 \mathrm{mg})$ of furosemide (Table 4). This agrees with previously reported results $[19,42]$. Similar findings were observed with regard to the effect of probenecid on the $\mathrm{CL}_{\mathrm{R}}$ of both tested doses of furosemide, with apparently no difference (Table S4 of the ESM) in the magnitude of effect. The substantial effect of probenecid on rosuvastatin exposure has recently been noted in cynomolgus monkeys, where AUC and $C_{\max }$ ratios of 2.6 and 3.5 were observed, along with a decrease in $\mathrm{CL}_{\mathrm{R}}$ of approximately $80 \%$ when rosuvastatin was administered as part of a cocktail with and without probenecid [43]. It is suggested that this interaction is due to rosuvastatin being a substrate of renal transporter OAT3 [44], which is inhibited by probenecid. Additionally, in vitro experiments showed inhibition of MRP2, OATP1B1, and OATP1B3 by probenecid [45-47]. Inhibition of these transporters may have contributed to the observed effect of probenecid on rosuvastatin; however, it is assumed that the major route of the interaction is based on OAT3, based on the $80 \%$ decrease of rosuvastatin $\mathrm{CL}_{R}$. As was to be expected mechanistically, probenecid had no relevant effect on the systemic exposure of digoxin or metformin. 

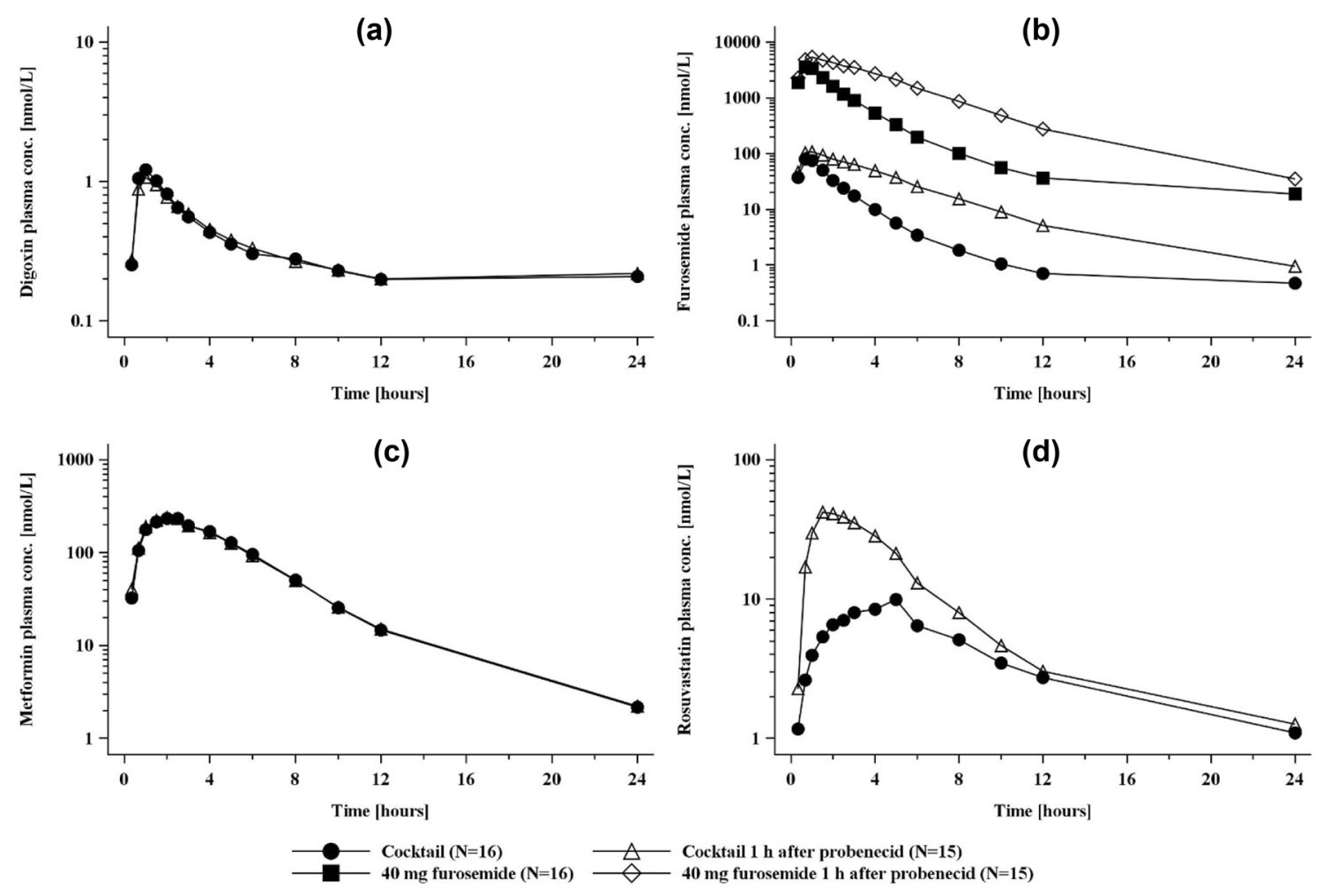

Fig. 3 Plasma concentration-time profiles (geometric mean) of a digoxin, $\mathbf{b}$ furosemide, $\mathbf{c}$ metformin, and $\mathbf{d}$ rosuvastatin after administration of a single oral dose of the cocktail given alone or in combi- nation with probenecid. Furosemide data are shown in addition for a therapeutic dose given with or without probenecid. conc. concentration

considered is that the transporter probe drugs are not only substrates for their target transporters, but also for other transporters. This is due to polyspecificity and overlapping substrate spectra of clinically relevant drug transporters: there are hardly any $100 \%$-specific transporter probe drugs approved for clinical use in the field. The specificity of the cocktail, in our opinion, is sufficient for its purpose as a screening tool. Clinical studies investigating the effect of new molecular entities on the transporter cocktail should assess both plasma and urine data, to allow discrimination between renal and extra-renal effects. In vitro data should be taken into account in the interpretation to allow further differentiation of the transporters involved in interactions detected by the cocktail. The use of biomarkers such as coproporphyrins may further inform the interpretation.

The marginal effect of verapamil on digoxin is considered to be based on the single-dose treatment of verapamil; in line with literature data [20], we expect that multiple verapamil dosing likely results in stronger effects on digoxin pharmacokinetics. Potential test compounds inhibiting P-gp could also be dosed to steady state before administering the cocktail. Digoxin behaved as expected with all other tested inhibitors. The 10-mg dose of metformin also behaved as expected under co-treatment with the tested inhibitors. 
Table 4 Trial part 3: adjusted geometric means (Adj. gMean), geometric mean ratios, and $90 \%$ confidence intervals (CIs) for the primary pharmacokinetic parameters of digoxin, furosemide, metformin, and rosuvastatin administered as a cocktail with and without the inhibitor probenecid

\begin{tabular}{|c|c|c|c|c|c|c|c|}
\hline \multirow[t]{3}{*}{ Endpoint } & \multicolumn{2}{|c|}{ Test $(T)$} & \multicolumn{2}{|c|}{ Reference (R) } & \multirow{3}{*}{$\begin{array}{l}\text { Ratio T/R } \\
\%\end{array}$} & \multirow{3}{*}{$\begin{array}{l}90 \% \mathrm{CI} \\
\%\end{array}$} & \multirow{3}{*}{$\begin{array}{l}\mathrm{gCV}^{\mathrm{a}} \\
\%\end{array}$} \\
\hline & \multicolumn{2}{|c|}{ Cocktail + probenecid } & \multicolumn{2}{|c|}{ Cocktail alone } & & & \\
\hline & $N$ & Adj. gMean & $N$ & Adj. gMean & & & \\
\hline \multicolumn{8}{|l|}{ Digoxin } \\
\hline $\mathrm{AUC}_{0-\mathrm{tz}}(\mathrm{nmol} \cdot \mathrm{h} / \mathrm{L})$ & 15 & 14.44 & 16 & 13.52 & 106.78 & $96.51-118.15$ & 15.5 \\
\hline$C_{\max }(\mathrm{nmol} / \mathrm{L})$ & 15 & 1.13 & 16 & 1.30 & 87.07 & $76.08-99.64$ & 20.9 \\
\hline \multicolumn{8}{|l|}{ Furosemide $^{\mathrm{b}}$} \\
\hline $\mathrm{AUC}_{0-\mathrm{tz}}(\mathrm{nmol} \cdot \mathrm{h} / \mathrm{L})$ & 15 & 483.38 & 16 & 177.96 & 271.63 & $246.74-299.03$ & 15.9 \\
\hline$C_{\max }(\mathrm{nmol} / \mathrm{L})$ & 15 & 110.64 & 16 & 90.00 & 122.94 & $110.25-137.09$ & 18.0 \\
\hline \multicolumn{8}{|l|}{ Metformin } \\
\hline $\mathrm{AUC}_{0-\mathrm{tz}}(\mathrm{nmol} \cdot \mathrm{h} / \mathrm{L})$ & 15 & 1331.83 & 16 & 1321.20 & 100.80 & $94.62-107.39$ & 9.6 \\
\hline$C_{\max }(\mathrm{nmol} / \mathrm{L})$ & 15 & 246.78 & 16 & 243.49 & 101.35 & $93.65-109.70$ & 12.0 \\
\hline \multicolumn{8}{|l|}{ Rosuvastatin } \\
\hline $\mathrm{AUC}_{0-\mathrm{tz}}(\mathrm{nmol} \cdot \mathrm{h} / \mathrm{L})$ & 15 & 238.16 & 16 & 106.69 & 223.24 & $203.79-244.55$ & 13.9 \\
\hline$C_{\max }(\mathrm{nmol} / \mathrm{L})$ & 15 & 43.29 & 16 & 10.11 & 428.23 & $359.78-509.70$ & 26.8 \\
\hline \multirow[t]{3}{*}{ Endpoint } & \multicolumn{2}{|c|}{ Test $(T)$} & \multicolumn{2}{|c|}{ Reference (R) } & \multirow[t]{2}{*}{ Ratio T/R } & \multirow[t]{2}{*}{$90 \% \mathrm{CI}$} & \multirow[t]{2}{*}{$\mathrm{gCV}^{\mathrm{a}}$} \\
\hline & \multicolumn{2}{|c|}{ Furosemide $^{c}+$ probenecid } & \multicolumn{2}{|c|}{ Furosemide alone $^{\mathrm{c}}$} & & & \\
\hline & $N$ & Adj. gMean & $N$ & Adj. gMean & $\%$ & $\%$ & $\%$ \\
\hline $\mathrm{AUC}_{0-\mathrm{tz}}(\mathrm{nmol} \cdot \mathrm{h} / \mathrm{L})$ & 15 & $25,741.38$ & 16 & 8503.07 & 302.73 & 274.99-333.27 & 15.9 \\
\hline$C_{\max }(\mathrm{nmol} / \mathrm{L})$ & 15 & 5699.67 & 16 & 3887.07 & 146.63 & $131.50-163.51$ & 18.0 \\
\hline
\end{tabular}

$A U C_{0-t z}$ area under the plasma concentration-time curve up to the last quantifiable concentration, $C_{\max }$ maximum plasma concentration, $g C V$ geometric coefficient of variation

${ }^{a}$ Within-subject gCV

${ }^{\mathrm{b}}$ Furosemide cocktail dose, $1 \mathrm{mg}$

${ }^{\mathrm{c}}$ Furosemide therapeutic dose, $40 \mathrm{mg}$

However, a lesser magnitude of a DDI effect was observed with the 10-mg dose of metformin compared with the 500$\mathrm{mg}$ dose. Given that the magnitude of change of the $\mathrm{CL}_{\mathrm{R}}$ of the two tested doses of metformin (under cimetidine dosing) was more similar, the 10-mg component of the cocktail is regarded as sufficient to detect a DDI with OCT2/MATE inhibitors and it is recommended to use the $\mathrm{CL}_{\mathrm{R}}$ and/or renal secretory clearance as a primary endpoint to detect any DDI effect of a perpetrator drug in metformin.

To overcome some of the discrepancies noted, the current transporter cocktail could be enhanced by the measurement of different endogenous biomarkers for drug transporters such as coproporphyrin I (OATP1B) and $\mathrm{N}^{1}$-methylnicotinamide (OCT2/MATE) [4]. Respective samples were taken in the current trial; investigations of these biomarkers are ongoing and will be published separately. Additional enhancements for the cocktail may include microdoses of midazolam, which could be added to investigate cytochrome P450 3A4 metabolic liability [48], as well as reducing the plasma and urine sampling to $36 \mathrm{~h}$ postcocktail administration to reduce the burden on subjects.

\section{Conclusions}

Overall, this study shows that the proposed transporter cocktail is an effective, safe, and reliable option to investigate clinical DDI potential compared to a series of single substrate/inhibitor studies.

Acknowledgements The authors thank Paul Tanswell for organizational and medical writing support during the preparation of this article and Anja Seifried for organization and programming of analysis datasets. We also thank Jashvant Unadkat, Walter E. Haefeli, and Yuichi Sugiyama for their expert advice.

\section{Compliance with Ethical Standards}

Funding The study was funded by Boehringer Ingelheim Pharma $\mathrm{GmbH} \& \mathrm{Co}$. KG, the sponsor of the trial.

Conflict of interest Kathrin Hohl and Edith Hauel were contracted by Boehringer Ingelheim as external statistician and external medical writer, respectively. Alen Jambrecina was the Principal Investigator contracted by Boehringer Ingelheim. Gerd Mikus and Martin F. 
Fromm have paid consultancy agreements with Boehringer Ingelheim. All other authors are employees of Boehringer Ingelheim.

Ethics Approval The clinical trial protocol was approved by the Independent Ethics Committee of the Chamber of Physicians of Hamburg, Germany, and the Federal Institute for Drugs and Medicinal Products (BfArM). The trial was carried out in compliance with the principles of the Declaration of Helsinki and in accordance with the International Council for Harmonization Guidelines for Good Clinical Practice.

Consent to Participate All subjects in the study provided written informed consent.

Open Access This article is licensed under a Creative Commons Attribution-NonCommercial 4.0 International License, which permits any non-commercial use, sharing, adaptation, distribution and reproduction in any medium or format, as long as you give appropriate credit to the original author(s) and the source, provide a link to the Creative Commons licence, and indicate if changes were made. The images or other third party material in this article are included in the article's Creative Commons licence, unless indicated otherwise in a credit line to the material. If material is not included in the article's Creative Commons licence and your intended use is not permitted by statutory regulation or exceeds the permitted use, you will need to obtain permission directly from the copyright holder. To view a copy of this licence, visit http://creativecommons.org/licenses/by-nc/4.0/.

\section{References}

1. Gessner A, König J, Fromm MF. Clinical aspects of transporter-mediated drug-drug interactions. Clin Pharmacol Ther. 2019;105(6):1386-94. https://doi.org/10.1002/cpt.1360.

2. Giacomini KM, Huang SM. Transporters in drug development and clinical pharmacology. Clin Pharmacol Ther. 2013;94(1):3-9. https://doi.org/10.1038/clpt.2013.86.

3. Giacomini KM, Huang SM, Tweedie DJ, Benet LZ, Brouwer KL, Chu X, et al. Membrane transporters in drug development. Nat Rev Drug Discov. 2010;9(3):215-36. https://doi.org/10.1038/ nrd3028.

4. Müller F, Sharma A, König J, Fromm MF. Biomarkers for in vivo assessment of transporter function. Pharmacol Rev. 2018;70(2):246-77. https://doi.org/10.1124/pr.116.013326.

5. EMA-CHMP. Guideline on the investigation of drug interactions: final (CPMP/EWP/560/95/Rev. 1 corr. 2). 2012. https://www. ema.europa.eu/docs/en_GB/document_library/Scientific_guide line/2012/07/WC500129606.pdf. Accessed 14 Jun 2019.

6. US FDA. In vitro drug interaction studies: cytochrome P450 enzyme- and transporter-mediated drug interactions guidance for industry. 2020. https://www.fda.gov/media/134582/download. Accessed 18 Jan 2020.

7. US FDA. Guidance for industry: clinical drug interaction studies: study design, data analysis, and clinical implications (draft guidance). 2017. https://www.fda.gov/media/82734/download. Accessed 14 Jun 2019.

8. Chainuvati S, Nafziger AN, Leeder JS, Gaedigk A, Kearns GL, Sellers E, et al. Combined phenotypic assessment of cytochrome p450 1A2, 2C9, 2C19, 2D6, and 3A, $N$-acetyltransferase-2, and xanthine oxidase activities with the "Cooperstown 5+1 cocktail". Clin Pharmacol Ther. 2003;74(5):437-47. https://doi.org/10.1016/ s0009-9236(03)00229-7.

9. Turpault S, Brian W, Van Horn R, Santoni A, Poitiers F, Donazzolo $\mathrm{Y}$, et al. Pharmacokinetic assessment of a fiveprobe cocktail for CYPs 1A2, 2C9, 2C19, 2D6 and 3A. Br J
Clin Pharmacol. 2009;68(6):928-35. https://doi.org/10.111 $1 / j .1365-2125.2009 .03548 . x$.

10. Stopfer P, Giessmann T, Hohl K, Sharma A, Ishiguro N, Taub $\mathrm{ME}$, et al. Pharmacokinetic evaluation of a drug transporter cocktail consisting of digoxin, furosemide, metformin, and rosuvastatin. Clin Pharmacol Ther. 2016;100(3):259-67. https://doi. org/10.1002/cpt.406.

11. Zhang L, Sparreboom A. Predicting transporter-mediated drug interactions: commentary on: "Pharmacokinetic evaluation of a drug transporter cocktail consisting of digoxin, furosemide, metformin and rosuvastatin" and "Validation of a microdose probe drug cocktail for clinical drug interaction assessments for drug transporters and CYP3A". Clin Pharmacol Ther. 2017;101(4):447-9. https://doi.org/10.1002/cpt.588.

12. Chu X, Liao M, Shen H, Yoshida K, Zur AA, Arya V, et al. Clinical probes and endogenous biomarkers as substrates for transporter drug-drug interaction evaluation: perspectives from the International Transporter Consortium. Clin Pharmacol Ther. 2018;104(5):836-64. https://doi.org/10.1002/cpt.1216.

13. Prueksaritanont T, Tatosian DA, Chu X, Railkar R, Evers R, Chavez-Eng C, et al. Validation of a microdose probe drug cocktail for clinical drug interaction assessments for drug transporters and CYP3A. Clin Pharmacol Ther. 2017;101(4):519-30. https:// doi.org/10.1002/cpt.525.

14. Trueck C, Hsin C-H, Scherf-Clavel O, Schaeffeler E, Lenssen R, Gazzaz M, et al. A clinical DDI study assessing a novel drug transporter phenotyping cocktail with adefovir, sitagliptin, metformin, pitavastatin and digoxin. Clin Pharmacol Ther. 2019;106(6):1398-407. https://doi.org/10.1002/cpt.1564.

15. Ebner T, Ishiguro N, Taub ME. The use of transporter probe drug cocktails for the assessment of transporter-based drug-drug interactions in a clinical setting-proposal of a four component transporter cocktail. J Pharm Sci. 2015;104(9):3220-8. https:// doi.org/10.1002/jps.24489.

16. Stopfer P, Giessmann T, Hohl K, Sharma A, Ishiguro N, Taub $\mathrm{ME}$, et al. Effects of metformin and furosemide on rosuvastatin pharmacokinetics in healthy volunteers: implications for their use as probe drugs in a transporter cocktail. Eur J Drug Metab Pharmacokinet. 2018;43(1):69-80. https://doi.org/10.1007/s1331 8-017-0427-9.

17. Stopfer P, Giessmann T, Hohl K, Hutzel S, Schmidt S, Gansser D, et al. Optimization of a drug transporter probe cocktail: potential screening tool for transporter-mediated drug-drug interactions. Br J Clin Pharmacol. 2018;84(9):1941-9. https://doi.org/10.1111/ bcp. 13609.

18. He YJ, Zhang W, Chen Y, Guo D, Tu JH, Xu LY, et al. Rifampicin alters atorvastatin plasma concentration on the basis of SLCO1B1 521T\%3eC polymorphism. Clin Chim Acta. 2009;405(1-2):4952. https://doi.org/10.1016/j.cca.2009.04.003.

19. Smith DE, Gee WL, Brater DC, Lin ET, Benet LZ. Preliminary evaluation of furosemide-probenecid interaction in humans. J Pharm Sci. 1980;69(5):571-5.

20. Pedersen KE, Dorph-Pedersen A, Hvidt S, Klitgaard NA, Pedersen KK. The long-term effect of verapamil on plasma digoxin concentration and renal digoxin clearance in healthy subjects. Eur J Clin Pharmacol. 1982;22(2):123-7.

21. Somogyi A, McLean A, Heinzow B. Cimetidine-procainamide pharmacokinetic interaction in man: evidence of competition for tubular secretion of basic drugs. Eur J Clin Pharmacol. 1983;25(3):339-45. https://doi.org/10.1007/bf01037945.

22. US FDA. Guidance for industry: bioanalytical method validation. 2001. https://www.fda.gov/downloads/drugs/guidancecomplia nceregulatoryinformation/guidances/ucm070107.pdf. Accessed 13 Mar 2017.

23. Kupper LL, Hafner KB. How appropriate are popular sample size formulas? Am Stat. 1989;43:101-5. 
24. Prueksaritanont T, Chu X, Evers R, Klopfer SO, Caro L, Kothare $\mathrm{PA}$, et al. Pitavastatin is a more sensitive and selective organic anion-transporting polypeptide $1 \mathrm{~B}$ clinical probe than rosuvastatin. Br J Clin Pharmacol. 2014;78(3):587-98. https://doi. org/10.1111/bcp.12377.

25. Lai Y, Mandlekar S, Shen H, Holenarsipur VK, Langish R, Rajanna P, et al. Coproporphyrins in plasma and urine can be appropriate clinical biomarkers to recapitulate drug-drug interactions mediated by organic anion transporting polypeptide inhibition. J Pharmacol Exp Ther. 2016;358(3):397-404. https://doi. org/10.1124/jpet.116.234914.

26. Reitman ML, Chu X, Cai X, Yabut J, Venkatasubramanian R, Zajic S, et al. Rifampin's acute inhibitory and chronic inductive drug interactions: experimental and model-based approaches to drug-drug interaction trial design. Clin Pharmacol Ther. 2011;89(2):234-42. https://doi.org/10.1038/clpt.2010.271.

27. Lau YY, Wu CY, Okochi H, Benet LZ. Ex situ inhibition of hepatic uptake and efflux significantly changes metabolism: hepatic enzyme-transporter interplay. J Pharmacol Exp Ther. 2004;308(3):1040-5. https://doi.org/10.1124/jpet.103.061770.

28. Kaneko K, Tanaka M, Ishii A, Katayama Y, Nakaoka T, Irie S, et al. A clinical quantitative evaluation of hepatobiliary transport of [(11)C]dehydropravastatin in humans using positron emission tomography. Drug Metab Dispos. 2018;46(5):719-28. https://doi. org/10.1124/dmd.118.080408.

29. Cho SK, Yoon JS, Lee MG, Lee DH, Lim LA, Park K, et al. Rifampin enhances the glucose-lowering effect of metformin and increases OCT1 mRNA levels in healthy participants. Clin Pharmacol Ther. 2011;89(3):416-21. https://doi.org/10.1038/ clpt.2010.266.

30. Belz GG, Doering W, Munkes R, Matthews J. Interaction between digoxin and calcium antagonists and antiarrhythmic drugs. Clin Pharmacol Ther. 1983;33(4):410-7. https://doi.org/10.1038/ clpt.1983.55.

31. Rodin SM, Johnson BF, Wilson J, Ritchie P, Johnson J. Comparative effects of verapamil and isradipine on steady-state digoxin kinetics. Clin Pharmacol Ther. 1988;43(6):668-72. https://doi. org/10.1038/clpt.1988.93.

32. Klein HO, Lang R, Weiss E, Di Segni E, Libhaber C, Guerrero J, et al. The influence of verapamil on serum digoxin concentration. Circulation. 1982;65(5):998-1003. https://doi.org/10.1161/01. cir.65.5.998.

33. Schwartz JB, Keefe D, Kates RE, Kirsten E, Harrison DC. Acute and chronic pharmacodynamic interaction of verapamil and digoxin in atrial fibrillation. Circulation. 1982;65(6):1163-70. https://doi.org/10.1161/01.cir.65.6.1163.

34. Pauli-Magnus C, von Richter O, Burk O, Ziegler A, Mettang T, Eichelbaum M, et al. Characterization of the major metabolites of verapamil as substrates and inhibitors of P-glycoprotein. J Pharmacol Exp Ther. 2000;293(2):376-82.

35. Cho SK, Kim CO, Park ES, Chung JY. Verapamil decreases the glucose-lowering effect of metformin in healthy volunteers. $\mathrm{Br}$ J Clin Pharmacol. 2014;78(6):1426-32. https://doi.org/10.1111/ bcp. 12476
36. Somogyi A, Stockley C, Keal J, Rolan P, Bochner F. Reduction of metformin renal tubular secretion by cimetidine in man. Br J Clin Pharmacol. 1987;23(5):545-51. https://doi. org/10.1111/j.1365-2125.1987.tb03090.x.

37. Wang ZJ, Yin OQ, Tomlinson B, Chow MS. OCT2 polymorphisms and in-vivo renal functional consequence: studies with metformin and cimetidine. Pharmacogenet Genom. 2008;18(7):637-45. https://doi.org/10.1097/FPC.0b013e3283 $02 \mathrm{~cd} 41$.

38. Kusuhara H, Ito S, Kumagai Y, Jiang M, Shiroshita T, Moriyama $\mathrm{Y}$, et al. Effects of a MATE protein inhibitor, pyrimethamine, on the renal elimination of metformin at oral microdose and at therapeutic dose in healthy subjects. Clin Pharmacol Ther. 2011;89(6):837-44. https://doi.org/10.1038/clpt.2011.36.

39. Crome P, Curl B, Holt D, Volans GN, Bennett PN, Cole DS. Digoxin and cimetidine: investigation of the potential for a drug interaction. Hum Toxicol. 1985;4(4):391-9.

40. Yamazaki M, Li B, Louie SW, Pudvah NT, Stocco R, Wong W, et al. Effects of fibrates on human organic anion-transporting polypeptide 1B1-, multidrug resistance protein 2- and P-glycoproteinmediated transport. Xenobiotica. 2005;35(7):737-53. https://doi. org/10.1080/00498250500136676.

41. Khamdang S, Takeda M, Shimoda M, Noshiro R, Narikawa S, Huang XL, et al. Interactions of human- and rat-organic anion transporters with pravastatin and cimetidine. J Pharmacol Sci. 2004;94(2):197-202. https://doi.org/10.1254/jphs.94.197.

42. Vree TB, van den Biggelaar-Martea M, Verwey-van Wissen CP. Probenecid inhibits the renal clearance of frusemide and its acyl glucuronide. Br J Clin Pharmacol. 1995;39(6):692-5.

43. Kosa RE, Lazzaro S, Bi YA, Tierney B, Gates D, Modi S, et al. Simultaneous assessment of transporter-mediated drug-drug interactions using a probe drug cocktail in cynomolgus monkey. Drug Metab Dispos. 2018;46(8):1179-89. https://doi.org/10.1124/ dmd.118.081794.

44. Windass AS, Lowes S, Wang Y, Brown CD. The contribution of organic anion transporters OAT1 and OAT3 to the renal uptake of rosuvastatin. J Pharmacol Exp Ther. 2007;322(3):1221-7. https:// doi.org/10.1124/jpet.107.125831.

45. Horikawa M, Kato Y, Tyson CA, Sugiyama Y. The potential for an interaction between MRP2 (ABCC2) and various therapeutic agents: probenecid as a candidate inhibitor of the biliary excretion of irinotecan metabolites. Drug Metab Pharmacokinet. 2002;17(1):23-33.

46. Matsushima S, Maeda K, Ishiguro N, Igarashi T, Sugiyama Y. Investigation of the inhibitory effects of various drugs on the hepatic uptake of fexofenadine in humans. Drug Metab Dispos. 2008;36(4):663-9. https://doi.org/10.1124/dmd.107.017814.

47. Hirano M, Maeda K, Shitara Y, Sugiyama Y. Drug-drug interaction between pitavastatin and various drugs via OATP1B1. Drug Metab Dispos. 2006;34(7):1229-366. https://doi.org/10.1124/ dmd.106.009290.

48. Halama B, Hohmann N, Burhenne J, Weiss J, Mikus G, Haefeli WE. A nanogram dose of the CYP3A probe substrate midazolam to evaluate drug interactions. Clin Pharmacol Ther. 2013;93(6):564-71. https://doi.org/10.1038/clpt.2013.27. 


\section{Affiliations}

Sabrina T. Wiebe ${ }^{1,5}$. Thomas Giessmann ${ }^{1} \cdot$ Kathrin Hohl ${ }^{1}$. Sven Schmidt-Gerets ${ }^{1}$ - Edith Hauel ${ }^{1}$ - Alen Jambrecina ${ }^{2}$. Kerstin Bader ${ }^{1} \cdot$ Naoki Ishiguro $^{3}$ - Mitchell E. Taub ${ }^{4} \cdot$ Ashish Sharma $^{4} \cdot$ Thomas Ebner $^{1} \cdot$ Gerd Mikus $^{5}$. Martin F. Fromm ${ }^{6} \cdot$ Fabian Müller $^{1,6} \cdot$ Peter Stopfer $^{1}$ [D

1 Boehringer Ingelheim Pharma GmbH \& Co. KG, Birkendorfer Str. 65, 88397 Biberach an der Riss, Germany

2 CTC North GmbH \& Co KG, University Medical Centre Hamburg Eppendorf, Hamburg, Germany

3 Kobe Pharma Research Institute, Nippon Boehringer Ingelheim Co. Ltd., Chuo-ku, Kobe, Japan

4 Boehringer Ingelheim Pharmaceuticals Inc., Ridgefield, CT, USA
5 UniversitätsKlinikum Heidelberg-Medizinische Klinik, Abteilung Klinische Pharmakologie and Pharmakoepidemiologie, Heidelberg, Germany

6 Institute of Experimental and Clinical Pharmacology and Toxicology, Friedrich-Alexander-Universität Erlangen-Nürnberg, Erlangen, Germany 